\title{
La real colegiata de san Juan de Caaveiro: nuevos datos sobre su arquitectura
}

\author{
Alberto Fernández González \\ Universidad de Sevilla
}

\begin{abstract}
RESUMEN. A pesar de las excavaciones arqueológicas llevadas a cabo en la Real Colegiata de San Juan de Caaveiro y del análisis detallado de una serie de documentos, su estudio histórico-artístico seguía presentando algunas incertidumbres, sobre todo porque no contábamos con ninguna planimetría antigua del edificio. Ahora, gracias al hallazgo de un valioso levantamiento de 1769 conservado en el Archivo Histórico Nacional, podemos conocer pormenorizadamente la primitiva configuración arquitectónica del monasterio.

Palabras clave: San Juan de Caaveiro, colegiata, patrimonio, Francisco Solinis, arquitectura religiosa.

ABSTRACT. Despite the archaeological excavations carried out at the John of Caaveiro Royal Collegiate Church and the detailed analysis of a series of documents, its historical and artistic study still posed some uncertainties, especially due to the fact that we did not have an old plan of the building. Nowadays, thanks to the discovery of valuable plans from 1760 preserved in the National Historical Archive, we know the primitive architectural structure of the monastery in detail.

Key Words: St. John of Caaveiro, collegiate church, heritage, Francisco Solinis, religious architecture.
\end{abstract}

“...la obra natural y la obra artística, al operar en mutua colaboración, están unidas por ambos lados y se enlazan entre si en mutua contemplación..."

(RICARDO DE SAN VÍCTOR, Beniamin Maior, siglo XII)

Las excavaciones arqueológicas llevadas a cabo en la real colegiata de San Juan de Caaveiro durante los meses de junio y julio de 1989 sacaron a la luz importantes hallazgos ${ }^{1}$. Aunque se descubrieron una serie de enterramientos y parte de los primitivos muros y se trazó la planta general del monasterio medieval (Fig. 1), la situación y configuración de algunos edificios, entre ellos la iglesia colegial, no pudo ser determinada con precisión. Con posterioridad, a partir de los datos obtenidos en la campaña de

-

${ }^{1}$ Sobre estas excavaciones patrocinadas por la Diputación Provincial de A Coruña y sus resultados, véase $\mathrm{R}$. VALDÉS-RAJOY, "1a campaña de excavación arqueológica en San Juan de Caaveiro", Cátedra, 3, 1996, pp. 213-242. excavación y del análisis detallado de algunos documentos significativos como dos dibujos del pintor Jenaro Pérez Villaamil y cuatro fotografías anteriores a 1896 , se pudo efectuar una reconstrucción hipotética del antiguo monasterio de canónigos regulares de San Agustín ${ }^{2}$ (Figs. 2 y 3). Con todo, y a pesar de las importantes aportaciones de estos últimos años ${ }^{3}$, el estudio histórico-artístico de Caaveiro seguía presentando el obstáculo insalvable de la restauración patrocinada por Pío García Espinosa a finales del siglo XIX, una remodelación que, como es conocido, contó con el asesoramiento de Antonio López Ferreiro y dio lugar a la alteración definitiva de la configuración original del complejo monástico, pues fueron demolidas las casas canonicales, la pieza destinada a las reuniones del cabildo, el archivo y el templo prin-

\footnotetext{
2 C. Castro Álvarez, "El monasterio de Caaveiro: dependencias y aspectos artísticos", Cátedra, 3, 1996, pp. 243-266.

${ }^{3}$ Debe ser destacado, en justicia, el espléndido monográfico que la revista Cátedra dedicó al monasterio en el año 1996.
} 
cipal, y además, aplicando el criterio historicista propio de la época, se reedificó la iglesia de Santa Isabel, la única que se conserva en la actualidad $^{4}$. Como hasta la fecha no se conocía ninguna planimetría antigua del monasterio ${ }^{5}$, cualquier intento reconstructivo entraba en el terreno de lo conjetural; pero ahora, gracias a un valioso plano que custodia el Archivo Histórico Nacional $^{6}$ (Figs. 4 y 5), delineado en octubre de 1769 por el ingeniero Francisco Solinis, podemos conocer pormenorizadamente cómo era la primitiva configuración edilicia de la colegiata y dar respuesta a algunos de los interrogantes que venía planteando el inmueble, como la ubicación, morfología y compartimentación interior de algunas estancias. Mi aportación, por tanto, se ceñirá al estudio del levantamiento arquitectónico y a dar a conocer una significativa descripción del cenobio, anterior en casi cien años a la de Montero Aróstegui ${ }^{7}$, la única detallada que poseíamos hasta el momento. Pero antes de analizar estos documentos, un breve apunte sobre el autor del plano.

FRANCISCO SOLINIS, MAESTRO DELINEADOR DEL CUERPO DE INGENIEROS MILITARES

El arquitecto e ingeniero Julián Sánchez Bort, como director del Arsenal de Ferrol $^{8}$, solicita en 1764 que le envíen dos "jovenes instruidos en la Delineacion para servir baxo sus ordenes en aquellas Reales obras de Mari-

-

${ }^{4}$ Al respecto, véase C. LUGILDE ARIAS Y J.F. CORREAARIAS, "Don Pío García Espinosa e o breve renacer de Caaveiro", Cátedra, 3, 1996, pp. 201-212. También A. López y CARBALleira, Misticos Gallegos. San Rosendo, Santiago, 1909.

${ }^{5}$ La complejidad de las fuentes, su valoración y una aproximación a los problemas que plantea la documentación en C. CASTRo Álvarez, "S. Juan de Caaveiro: estado de la cuestión, fuentes, historia y problemas", Cátedra, 3, 1996, pp. 21-62.

${ }^{6}$ Archivo Histórico Nacional (en adelante A.H.N.). Sección Consejos. Planos, mapas y dibujos, $\mathrm{n}^{\circ} 640$.

7 J. Montero Aróstegui, Historia y descripción de la ciudad y departamento naval del Ferrol, Madrid, 1859, pp. 654-657.

${ }^{8}$ Fue nombrado director en 1762 , en sustitución del ingeniero Francisco Llobet. Sobre la actividad desplegada por Sánchez Bort en su etapa ferrolana, véase A. VIGO TRASANCOS, "El arquitecto-ingeniero Julián Sánchez Bort: perfil biográfico y obra en Galicia", Cuadernos de Estudios Gallegos, 100, 1984-85, pp. 501-525; Arquitectura y urbanismo en el Ferrol del siglo XVIII, Vigo, 1985, pp. 64-71, 74$83,179-184,210-224$. na" ${ }^{9}$. A instancia de la Academia de Bellas Artes de San Fernando, se le asignan dos ayudantes -ambos discípulos aventajados de arquitectura-, que fueron destinados a las obras del Departamento con el grado de delineador ${ }^{10}$ : uno de estos técnicos se llamaba Antonio Bada y Navajas, el otro, Francisco Solinis ${ }^{11}$.

Aunque la biografía de Solinis se ignora en gran medida, gracias a las investigaciones de Pérez Rodríguez ${ }^{12}$, conocemos importantes datos relativos a su formación ${ }^{13}$, méritos ${ }^{14} \mathrm{y}$

-

${ }^{9}$ C. BÉDAT, La Real Academia de Bellas Artes de San Fernando (1744-1808), Madrid, 1989 [1 $1^{\mathrm{a}}$ ed., Toulouse, 1977], p. 213. También A. QUINTANA MARTínEZ, La Arquitectura y los arquitectos en la Real Academia de Bellas Artes de San Fernando (1744-1774), Madrid, 1983, pp. 90$91,144$.

${ }^{10}$ En enero de 1740 se había creado la clase de delineadores, grado con el que se ingresaba en el cuerpo de ingenieros militares. En la época en que Solinis trazó el plano de Caaveiro, la corona contaba con 110 ingenieros (10 directores, 10 en jefe, 20 en segundo, 30 ordinarios y 40 extraordinarios) y 40 delineadores, alcanzando el cuerpo un total de 150 miembros. Véase, al respecto, H. CAPEL, J.E. SÁNCheZ y O. MoncadA, De Palas a Minerva. La formación cientifica y la estructura institucional de los ingenieros militares en el siglo XVIII, Barcelona, 1988, pp. 55, 70.

${ }^{11}$ C. BÉDAt, La Real Academia..., p. 213. También A. Vigo TRASANCOS, Arquitectura y urbanismo en el Ferrol..., pp. 12-15, 180, 198.

${ }^{12}$ F. PÉREZ RoDríGUEZ, "El arquitecto e ingeniero Francisco Solinis a través de su curriculum", Abrente, 29, 1997, pp. 117-125.

${ }^{13}$ Además de conocer la lengua francesa, estudió gramática latina, matemáticas y física experimental con los jesuitas, y tres años de filosofía con los dominicos. Solinis asistió tempranamente a las "clases de diseño de figura" que se impartían en la Real Academia de San Fernando. Con posterioridad, en 1758, tras un abandono temporal de los estudios, retomaría su formación en la "academia privada" del escultor Felipe de Castro. Por estas fechas vuelve a frecuentar la Academia de Bellas Artes, pero ahora interesado en la arquitectura civil. $c f r$. F. PÉREZ RodríGUEZ, "El arquitecto e ingeniero Francisco Solinis...”, p. 118.

${ }^{14} \mathrm{La}$ Real Academia le concedió un pensionado en la corte durante cuatro años, obteniendo, asimismo, dos premios en concursos oficiales. En 1764 inició su carrera profesional como delineante en el cuerpo de ingenieros militares. Cuatro años más tarde es habilitado como arquitecto y, con posterioridad, en 1771, cuando Sánchez Bort abandonó Ferrol, es nombrado arquitecto. A principios de 1781, antes de iniciar su etapa cántabra en las Reales Fábricas de Artillería de hierro colado de La Cavada, es designado ingeniero y luego fiscal-facultativo. También obtiene el grado de alférez de fragata, el de alférez de navío y otros cargos honoríficos. En 1801 solicita su admisión como "uno de los Académicos de Mérito de la Real Academia de San Fernando en la clase de Arquitecto Civil, o Hidráulico". cfr. F. PÉREZ RODRíGUEZ, "El arquitecto e ingeniero Francisco Solinis...”, pp. 117-123. 
producción artística ${ }^{15}$. El ingeniero era natural de la villa de Madrid y su nacimiento debe fecharse en torno al año 1743. Por tanto, cuando Francisco Solinis llevó a cabo el levantamiento de la colegiata de San Juan de Caaveiro, tendría unos 26 años, y seguía desempeñando en Ferrol, a las órdenes de Sánchez Bort, las funciones inherentes a su cargo con un resultado plenamente satisfactorio, pues, el 5 de mayo de 1768 , había obtenido la habilitación como arquitecto "para exercer las funciones correspondientes de mediciones particulares y generales, a la conclusion de cada uno de los edificios, y el mecanismo a tan vastas obras" 16 .

\section{LA REAL COLEGIATA EN OCTUBRE DE 1769}

El plano de Francisco Solinis se sitúa en un contexto histórico muy concreto: el primer intento de traslado de la real colegiata a Pontedeume o Ferrol. En julio de 1769 Antonio Arias Somoza, dignidad de la catedral de Mondoñedo, visita San Juan de Caaveiro ${ }^{17}$. La Real Cámara le había encargado "la visita de la Colegial de Caveyro y la formacion de estatutos", con el mandato expreso de reconocer el monasterio y dar cuenta detallada de su estado. El escribano Francisco Pérez Velderrain, que acompañaba al mencionado arcediano de la basílica mindoniense en su inspección, tomó buena nota de todas las diligencias efectuadas en el cenobio, entre las que se incluía "deliniar y formar un diseño,

\footnotetext{
15 Aunque por falta de datos no se puede establecer con precisión su intervención, sabemos que participó activamente en numerosas obras y proyectos, tanto en su etapa ferrolana como en la cántabra, y a tenor de la relación documental que transcribe F. PÉREZ RODRÍGUEZ, "El arquitecto e ingeniero Francisco Solinis...”, pp. 120-121, no cabe duda de que el diseño y levantamiento de planos fue una actividad fundamental en su carrera profesional. De hecho, Pérez Rodríguez menciona algunos croquis del ingeniero -en su relación no figura el plano de San Juan de Caaveiro- que fueron catalogados en su momento por C. SAMBRICIO, Territorio y ciudad en la España de la Ilustración. Relación de mapas, documentos y manuscritos, Madrid, 1991, p. 130.

${ }^{16}$ F. PÉREZ RODRÍGUEZ, "El arquitecto e ingeniero Francisco Solinis...”, p. 120.

${ }^{17}$ El Archivo Histórico Nacional (Sección Consejos, leg. 16189) custodia el expediente que el arcediano de Mondoñedo envió a la Cámara Real. El plano de Solinis formaba parte de este documento. También se conserva alguna documentación sobre esta visita a Caaveiro en el Archivo del Reino de Galicia (leg. 20942/20), según señaló J.F. CORREA ARIAS, "Caaveiro e a crise do Antiguo Réxime", Cátedra, 3, 1996, pp. 194-195, y en el Archivo Histórico Diocesano de Santiago (Fondo General. Colegiatas, carp. 366), como indicó C. CAStro Álvarez, "S. Juan de Caaveiro: estado de la cuestión...", p. 56.
}

o mapa del terreno, positura, y situacion deste monasterio, a efecto de hauer constar de ello a Su Majestad según ordena por su real zedu$l a^{\prime 18}$. Los comisionados llegan a la colegiata el 27 de julio, y poco después, según recoge el notario, "el señor visitador escribio carta politica al cauallero yntendente de Marina del Departamento del Ferrol, distante de aqui tres leguas, noticiandole la Real Orden de S. M. para que le remitiese uno de los maestros deliniadores a fin de executarlo, y con efecto ymbio uno que dijo llamarse Don Francisco Solinis, quien estubo aquí algunos dias, y andubo con mi asistencia, y la del señor visitador reconociendo uno y otro y tomando sus medidas para executarlo"19. No puedo fechar con exactitud la llegada del ingeniero a Caaveiro, pero, en todo caso, el 29 de agosto abandonó el monasterio para reincorporarse a sus ocupaciones habituales en el Departamento marítimo, llevando, eso sí, "las medidas, y quedando de por ellas formar alla el diseño y remitirlo"20.

El reconocimiento y descripción de montañas, ríos, puentes y caminos era una práctica habitual de los ingenieros militares que estaba regulada por el título segundo del reglamento cuarto de las ordenanzas, que establece el "método que debe observarse en el levantamiento y formación de mapas y planos"21. Solinis orienta su croquis de sur a norte, quizá para facilitar la descripción geográfica del enclave, reproduciendo en detalle el entorno natural de la colegiata (Fig. 4), un paraje definido, qué duda cabe, por los montes cercanos, el río Eume y su afluente, el Sesín, y el promontorio rocoso donde se asienta el viejo edificio medieval. En el sector inferior del dibujo se distingue claramen-

18 A.H.N. Sección Consejos, leg. 16189, fols. 53-54.

19 idem, fol. 54

20 "[Solinis] expuso de restituirse a la Reales Obras, se partio oy a ellas [29 de agosto de 1769], llebando las medidas, y quedando de por ellas formar alla el diseño y remitirlo" (ibidem).

${ }^{21}$ El reglamento establece, en líneas generales, que los levantamientos de "Iglesias y demas edificios deben tener una escala en que sean perceptibles hasta los menores detalles; cuya regla ha de observarse particularmente en los perfiles de unos y otros: En todos estos planos se colocará la brúxula, á fin de que se forme justa idea de los parages del edificio mas expuestos á los nortes, ú otros vientos ó aguas reynantes en el pais" (Ordenanza que S. M. manda observar en el servicio del Real Cuerpo de ingenieros, Madrid, 1803, pp. 203-204). 
te la sinuosa vereda antigua ${ }^{22}$ que atravesaba los bosques y collados de la comarca ${ }^{23}$ y que desde As Neves permitía el acceso al monasterio por Pousadoiro $^{24}$. A la izquierda, en medio de las montañas, podemos apreciar el "camino, que baxa á passar el Puente del Rio Heume,25, una senda que, al menos en su recorrido final, coincide con el acceso moderno ${ }^{26}$. También se localizan en el plano "Varios Sitios de Viñas, y tierras de labor" ${ }^{27}$, y el viejo puente de piedra sobre el Sesín, todavía en buen uso en la actua$\operatorname{lidad}^{28}$. No figura, sin embargo, el molino de la margen izquierda del río, un edificio, hoy arruinado, construido con posterioridad, por tanto ${ }^{29}$. Una vez cruzado el puente, el camino dibuja una curva hacia el oeste, en dirección al monasterio, y se llega, después de superar un pronunciado ascenso, a la pequeña plataforma que, a modo de terraza, organiza el espacio situado entre el horno $^{30}$ y las caballerizas ${ }^{31}$, y donde, según

22 "A. Camino que va de Ferrol al Santuario" (cfr. Apéndice documental).

${ }^{23}$ Concretamente, los montes de Vinizón, Pena Mala y Pardineira: "\&. Monte de Vininzon/ W. Ydem de Penamala/ Ydem de Pardineyra". Los dos primeros, ya aparecen mencionados en documentos altomedievales, que también identifican el afluente del Eume con el nombre de "Sisín", como hace el ingeniero en su croquis. Al respecto, véase $\mathrm{C}$. Castro Álvarez, "Historia", en El monasterio de San Juan de Caaveiro, A Coruña, 1999, p. 15. En el tercer monte -el denominado "Pardineyra"-, si tenemos en cuenta los símbolos codificados que figuran en el reglamento de ingenieros militares, se localizaría una mina de hierro (Ordenanza que S. M. manda..., p. 210).

${ }^{24}$ Sobre los caminos de acceso a la colegiata, véase C. Castro Álvarez, "Historia", en El monasterio..., pp. 1517.

${ }^{25}$ En el abecedario aparece señalado con la letra Z ( $c f r$. Ap. doc.).

${ }^{26}$ Sin embargo, curiosamente, la descripción de 1859 de J. Montero Aróstegui, Historia y descripción..., p. 654, sólo menciona el camino antiguo que atraviesa el puente sobre el afluente del Eume: "Un puente de buena sillería, levantado sobre el Sesín, da entrada al peñón, por el pequeño istmo, y este es el único paso que tiene la colegiata".

27 Se señalan con la letra Y (cfr. Ap. doc.).

28 "B. Puente" (cfr. Ap. doc.).

${ }^{29}$ No cabe duda de que en el año 1769 el molino no estaba edificado porque el reglamento del cuerpo obligaba a hacer "mencion de los molinos de qualquiera especie" (Ordenanza que S. M. manda..., p. 206).

30 "T. [Horno]" (cfr. Ap. doc.). Según una referencia documental del año 1739, "en el circuito de dicha yglesia y convento no ay mas vecinos que vno, que sirve a los canonigos de panadero, y labandero, y tanbien de sacristan". cfr. Archivo Histórico Diocesano de Santiago (en adelante A.H.D.S.). Fondo General. Colegiatas, carp. 366, s. f. A algunos metros de distancia, hacia el este, aparece localizada en el plano una fuente ("X. Fuente". cfr. Ap. doc.). indica Solinis, "á mucha costa se puede edificar $^{, 32}$.

La pormenorizada planta de la real colegiata de San Juan de Caaveiro ocupa el extremo occidental del promontorio ${ }^{33}$ (Fig. 5). Gracias al esmerado trabajo del ingeniero podemos conocer la compartimentación y ubicación exacta de las tres primeras casas canonicales ${ }^{34}$, situadas, como se sospechaba, entre la portería de abajo ${ }^{35}$ y la iglesia de Santa Isabel $^{36}$, y constatar su directa comunicación con el corredor escalona$\mathrm{do}^{37}$ que servía de paso hacia la portería alta ${ }^{38}$.

Ocupando el mismo lugar que la reconstruida a finales del ochocientos, completamente adosada a los muros septentrionales de contención y con su semicírculo absidial cegado por la proximidad de la casa más occidental de los canónigos, se disponía la denominada iglesia antigua o de Santa Isabel ${ }^{39}$. Aunque sus dimensiones eran menores que las de la iglesia colegial, tenía, no obstante, como demuestra la esca-

\section{-}

31 "S. Cavall[erizas]" (cfr. Ap. doc.).

32 "C. Sitio que sirve de entrada, donde á mucha costa se puede edificar" (cfr. Ap. doc.)

33 También señala el técnico la diferencia de altura existente entre el extremo oriental de la plataforma, donde localiza el horno, y el occidental, donde sitúa el monasterio: "El piso del Collegio se halla cincuenta pies mas alto, que el del Horno T' (cfr. Ap. doc.)

34 "[F. Havi] taciones para los seis Prebenda[dos]" (cfr. Ap. doc.). Según consta en un documento de 1739, "en la yglesia de san Juan de Cabeiro ai seis canonigos, que residian cada uno en su habitazion inmediatas a dicha yglesia con un criado para su asistencia, y todos los dias tienen misa cantada, que se reparte entre ellos por semanas [...] a que comunmente asisten solos, por no tener capellan ni ministro alguno diputado en dicha yglesia para su asistencia" (A.H.D.S. Fondo General. Colegiatas, carp. 366, s. f.).

35 "D. Unica entrada para el Collegio" (cfr. Ap. doc.).

36 “M. Yglesia que no tiene uso" (cfr. Ap. doc.).

37 "E. [Comu]nicacion para entrar a las havi[tac]iones, y paso preciso para la Yglesia" (cfr. Ap. doc.).

38 "R. Coro [...] subida para la Torre" (cfr. Ap. doc.). Encima de esta portería se levanta la torre barroca, construida posiblemente, como señaló en su momento Ma.C. FOLGAR DE LA CALLE, Arquitectura gallega del siglo XVIII. Los Sarela, Santiago, 1985, pp. 84-86, a partir de un diseño del arquitecto Clemente Sarela. Este campanario sustituyó a otro anterior que, a partir de un inventario de 1704, logró documentar C. CASTRO Álvarez, "El monasterio de Caaveiro: dependencias...", p. 254.

${ }^{39}$ Sobre los restos que perduran del primitivo santuario románico, véanse R. YZQUIERdo PERRÍn, Arte Medieval I. Galicia. Arte, vol. X, A Coruña, 1993, pp. 288-291; y C. CAStro Álvarez, "El monasterio de Caaveiro: dependencias...", pp. 261-266. 
la, una mayor anchura. Ahora bien, este viejo edificio románico había sido modificado en 1738 , cuando el prior del monasterio, "atendiendo a que el cuerpo de la iglesia de Sta. Isabel no sirve para ministerio alguno por aver zerrado al fin", decidió que era imprescindible construir "un quarto y morada con cozina $y$ camareras y servicio posible que sirba de Hospederia para los devotos huespedes y Priores, o si en algún tiempo se aumentara el numero de los Canonigos, y que se ponga en toda perfeción $y$ alajas porque desde luego se pueda habitar en el" 40 . Del primitivo santuario, en la fecha en que se levantó el plano, sólo quedaba en pie la parte correspondiente a su mitad oriental ${ }^{41}$, pues la occidental había sido remodelada completamente para albergar la sala del capítulo ${ }^{42}$ y las nuevas dependencias del $\operatorname{archivo~}^{43}$. Y justo encima de estas dos piezas renovadas se disponía " $u n$ segundo piso que sirve de estrecha Havitacion, cuando concurre el Prior, y tiene la entrada por el Coro" ${ }^{44}$.

La representación gráfica de la iglesia colegial $^{45}$ es verdaderamente relevante porque, hasta ahora, se ignoraba su estructura y exacto emplazamiento. El levantamiento de Francisco Solinis permite constatar que la planta del templo, longitudinal, de nave única y ábside semicircular, estaba orientada litúrgicamente hacia el este. Más larga y menos ancha que la iglesia de Santa Isabel, contaba con cuatro altares: el mayor, como no podía ser de otra manera, instalado en la cabecera ${ }^{46}$; otro en el lado de la Epísto-

-

${ }^{40}$ C. CAstro Álvarez, "El monasterio de Caaveiro: dependencias...”, p. 258

${ }^{41}$ Francisco Solinis señala incluso el altar mayor del templo. El retablo, de estilo barroco, debe fecharse en 1623 , según la inscripción que figuraba en el mueble. Todavía perduraba en el ochocientos, cuando visitó el monasterio J. Montero Aróstegui, Historia y descripción..., p. 655.

42 "N. Sala de Capitulo" (cfr. Ap. doc.).

43 "O. Archivo" (cfr. Ap. doc.)

44 “Encima del Archivo O. y Sala de juntas, N, hay un segundo piso que sirve de estrecha Havitacion, cuando concurre el Prior, y tiene la entrada por el Coro R" (cfr. Ap. doc.).

45 "J. Yglesia" (cfr. Ap. doc.).

${ }^{46}$ El retablo mayor de la colegial de Caaveiro fue encargado en 1705 y su construcción se inició al año siguiente. Al respecto, véase C. CASTRO Álvarez, "El monasterio de Caaveiro: Dependencias...", p. 257. Gracias a los datos que recopiló J. MONTERO ARÓSTEGUI, Historia y descripción..., pp. 654-655, podemos conocer su iconografía: "El retablo del altar mayor esta dorado y en buen estado de conservación. En él existen las efigies de Santa Isabel, reina de Ungria, con otras mas pequeñas de San Pedro y San Pablo: la, donde casi con toda seguridad se ubicaba el órgano ${ }^{47}$; y dos más en el lado del Evangelio ${ }^{48}$. También comprobamos que, aparte de la entrada principal, situada en la fachada occidental del santuario y en directa comunicación con el atrio que se disponía a sus pies ${ }^{49}$, existía otro acceso secundario en el frente sur. En este flanco de la iglesia se emplazaba asimismo la sacristía ${ }^{50}$, cuadrangular y bastante espaciosa para las pequeñas dimensiones del edificio. Se debe señalar, por último, que el templo principal de Caaveiro no estaba adosado a la muralla ni a ninguna otra construcción y podía ser recorrido en su totalidad gracias a un "corredor que sirve de paso" $"$.

Anexas a la muralla de contención, en el sector meridional del complejo monástico, se localizaban en 1769 dos piezas en calamitoso estado de conservación: un salón, que servía “de Yglesia en los concursos de Romerias" " ${ }^{\text {, prácti- }}$ camente desmoronado en esa fecha debido al "pie y medio de desplome" que tenía el muro perimetral $^{53}$; y una "casa arruynada" y sin tabi-

al lado derecho se ve la imagen de San Juan Bautista, patrón de dicha iglesia, y al izquierdo la de San Agustín, obispo, a cuyo orden de canónigos seglares pertenecen los de esta colegiata. Sobre el ático del altar descuella un escudo de las Armas Reales".

47 "En el coro hay una silleria con nueve asientos, en cuyo centro aun existe un antiguo facistol. Sobre el costado derecho sigue una balconada, continuación de la del coro, donde acaso estaría el órgano". cfr. J. MONTERO ARÓSTEGUI, Historia y descripción..., pp. 654-655. Los canónigos solicitan en el verano de 1739 la dotación de una plaza de organista, contemplándose "mil ducados de renta, los 600 aplicados para la referida prebenda de oposicion, y los 400 restantes para manutencion del organista, fabrica, y reparos del organo" (A.H.D.S. Fondo General. Colegiatas, carp. 366 , s. f.).

${ }^{48}$ En el siglo XIX habían desaparecido estos retablos colaterales, según constató en su momento J. MONTERO ARÓSTEGUI, Historia y descripción..., p. 655.

49 "I. Atrio descubierto delante de la Yglesia" (cfr. Ap. doc.).

50 "K. Sacristia" (cfr. Ap. doc.). Cabe la posibilidad de que esta pieza se hubiese reubicado y, antiguamente, estuviese emplazada en otro lugar. En todo caso, la sacristía que reproduce Francisco Solinis en su plano fue construida en 1705. Debajo de la vicaría, "hay varios subterráneos oscuros que parecen calabozos y lo mismo en el gran patio que existe a la entrada del edifico, pero estos de mayores dimensiones y con luz y rejas al exterior" (J. MONTERO ARÓSTEGUI, Historia y descripción..., p. 655).

51 "L. Corredor que sirve de paso" (cfr. Ap. doc.).

52 "P. Salon arruynado que sirve de Yglesia en los concursos de Romerias" (cfr. Ap. doc.).

53 " $Q$. Pared con pie y medio de desplome azia adentro que causa la ruyna de dicho Salon" (cfr. Ap. doc.). 
cación interior, ubicada a continuación ${ }^{54}$. La planimetría se completa con otros dos inmuebles situados en el extremo occidental del promontorio, uno habilitado como alojamiento de prebendados ${ }^{55}$, y el otro todavía en fase de construcción $^{56}$.

\section{LA DESCRIPCIÓN DEL MONASTERIO Y OTROS DOCUMENTOS}

En el expediente que el arcediano de Mondoñedo envió a Madrid figuran todas las diligencias efectuadas con motivo de la visita a la colegiata. Me parece oportuno dar a conocer una interesante descripción del enclave -a pesar de que reitera algunos aspectos arquitectónicos ya señalados- porque completa y corrobora la información gráfica estudiada. Otras noticias significativas, también recogidas en los autos oficiales, se refieren a la escasa asistencia regular de fieles, las reformas proyectadas por el maestro carpintero Manuel Fandiño y a una curiosa exploración de los alrededores de Caaveiro.

La fecha escogida para llevar a cabo la inspección ocular del cenobio agustino fue el 29 de agosto. Según certifica el notario que acompañaba a Antonio Arias en su visita, reconocieron, "con todo cuidado, la positura, situacion, y terreno de este monasterio, y es en esta manera: Situacion. Es una montaña aspera, y desierta, que componen diferentes montes altos en circunferencia, teniendo todos su declibio rapido y elevado al fondo de un rio crecido, que por medio de ellos vaja a la villa de Puente deume, su ria, y puertos que auajo de ella ay formando un oyo profundo cubierto de las mismas sierras, $y$ montes, sin tener la vista otro objecto; en medio se halla edificado el monasterio sobre peña viua circundado del rio por el mediodia, y de otro que de la sierra vaja a el por el norte, y poniente, am[b]os mui proximos, y el comvento elevado sobre ellos, por las mas de las partes quasi perpendicularmente en mas de ducientas varas de altura poblado de espesura de arboles $y$ otras malezas, y de yedras que ya suben a los tejados, siendo madriguera de culebras, y otras savandijas, desde cuio plano del comvento sus corredores, y ventanas desvaneze la vista al

-

54 “G. Casa arruynada” (cfr. Ap. doc.)

55 "[F. Havi]taciones para los seis Prebenda[dos]" (cfr. Ap. doc.)

56 "H. Casa por concluir" (cfr. Ap. doc.). mirar para auajo al ondo de los rios al que no esta acostumbrado y se asoma a sus orillas por ser un precipicio tal que es inreparable la vida de alguno si cae: Solo tiene la entrada por la vajada de una de las sierras a la parte del oriente por donde se entra subiendo en cuesta, y por tres tiros de escaleras para entrar en el primitivo, ademas de otras que aun ay dentro: Esta entrada al principio fuera es mui angosta por la qual cave poco mas que un carro, teniendo de un lado, y de otro el mismo despenadero aunque a la parte del mediodia en algunos ferradillos que ay entre las penas, y por encima de ellas tienen los canonigos algunas plantas frutiferas, y ortaliza, teniendo de hambas partes a los lados petriles de pared porque no se cayga la gente, y el de la parte del norte al presente arruinado: Desde esta garganta o entrada de afuera se va ensanchando la peña y sitio del comvento a modo de calavaza, o pala de un barquin de errero en la que estan fundadas dos yglesias primero a la entrada una con la adbocacion de Visitazion de Nuestra Señora y santa Ysabel, y adelante de esta mediando un corto transito la del glorioso San Juan Baptista en donde celebran los oficios divinos, y por remate adelante de ella las casas, y avitaziones de tres canonigos la una havitable, y las dos reedificandose actualmente: Antes de la puerta y entrada al primitivo monasterio e yglesias, ay primero otra puerta que es la principal entrada, y que cierra todo, desde la qual a la otra ay otras tres havitaciones de canonigos que por arriba en los pisos ocupan todo el ancho de una a otra pared, por deuaxo de los quales ay una calleja libre de puerta a puerta por donde se sube y vaja. Y esta es la positura de la situacion y terreno, y para hacerla demostrable por deseño y planta según arte ${ }^{, 57}$.

Aparte de la ineludible referencia al entorno montañoso y la constatación de algunas características del monasterio ya conocidas, como su disposición en un espacio reducido $\mathrm{y}$ en pendiente, circunstancia que determina el escalonamiento del edificio en terrazas, el pasaje anterior aporta algunos datos arquitectónicos complementarios, que documentan, por ejemplo, el estado ruinoso del sector septentrional de los muros de contención y la remodelación de dos de las tres casas canonicales ubicadas en el extremo occidental del recinto. Otro apartado del informe menciona concisamente los templos

${ }^{57}$ A.H.N. Sección Consejos, leg. 16189, fols. 53-54. 
románicos: "las dos yglesias son construidas de cantera, y sus capillas maiores de bobeda $y$ ambas con poca diferencia de un tamaño, y de una misma fabrica y orden, indicando su antiguedad que tenia", y la pequeña torre barroca situada, como sabemos, encima de la portería alta, que contaba en ese momento de su historia con tres campanas, "y una de ellas ronpida de las quales la una sirbia para las oras del relox que tambien ay; pero sin uso por estar desconpuesto, y según dizen de algunos años a esta parte ${ }^{58}$. Más pormenorizadamente se describe la estancia adosada a la muralla meridional, ubicada justo enfrente de la sacristía de la iglesia colegial, y ya arruinada en esa época -quizá, como se apunta, porque fue utilizada como cantera para otras edificaciones-, que tanto en la documentación como en el plano de Francisco Solinis ${ }^{59}$ es identificada con el nombre de salón: "El salon que se halla en par de ellas pareze según dizen serbia de cavildo o de lo mismo que los porticos, o atrios de las yglesias, el qual se halla con piso de tabla ya viexo, y lo mas de el hueco por auajo en mas de treinta quartas de profundidad, socavada en la misma peña, lo que demuestra haver sido a mano, y acaso para con la piedra que arrancaron del sitio hazer otras obras, cuia pared maestra del costado que dize al mediodia tiene cinco bentanas muy capazes, y se halla arruinada, desplomando adentro desde las vigas del fayado al piso media vara con algunas silbas por las quales se introduzen las yedras, hallandose al mismo tiempo falsas y arruinadas las vigas de arriba tabla, y pontones, de manera que es mui temible su ruina, y caida cada momento, y por lo mismo necesita su reparacion de nuebo haviendo de subsistir" ${ }^{\prime 60}$.

La asistencia regular de fieles a los oficios religiosos que se celebraban en la colegiata era escasa. De hecho, según refiere el escribano, ni él ni Ares habían visto "concurso de personas algunas a misa, ni a los oficios divinos mas que los domesticos, y familiares del señor Visitador, y sólo aier [28 de agosto] hubo con el motibo de ser la festividad de San Agustín concurrieron algunas personas de las aldeas circonvezinas, formando una romeria de las que con abuso suele hauer por este, y otros paises, ocasionan-

58 idem, fols. $54-54 \mathrm{v}$

${ }^{59} \mathrm{La}$ estancia es señalada con la letra P. " $P$. Salon arruynado que sirve de yglesia en los concursos de romerias" (cfr. Ap. doc.)

${ }^{60}$ A.H.N. Sección Consejos, leg. 16189, fols. 54-54 v. do mas escandalo que edificazion, siendo su fin e intento de concurrir el juntarse para meriendas, bayles, y otras cosas, que motivo de verdadera devoción al santuario; y solo estando ya en la misa maior, y al sermon que se predico del santo a ella, la que se dijo, y celebro en el citado salon ${ }^{61}$, y un altar indezente que esta en la cabezera de el $l^{62}$, llego el parroco de esta parroquia revestido con pelliz, y capa plubial, su cruz, y estandarte, $y$ sus feligreses en procesion cantando las letanias mayores, que fue lo que hizo maior el concurso, y preguntando el señor visitador la causa de esta procesión, se le respondio executarlo en cumplimiento de una horden circular del señor Arzobispo de Santiago a toda su diocesis a efecto de inplorar la Divina misericordia en tantas enfermedades epidemicas, como se padecieron, y padezen por estos paises: $Y$ hauiendo el señor visitador tomado razon de varias personas, si a excepcion de la precision referida en semejantes dias los años anteriores era ygual o mayor el concurso y otro el fin de el, conformemente respondieron ser el mismo" ${ }^{\prime 63}$.

Francisco Pérez y Antonio Ares permanecieron varios meses en Caaveiro, pues el ingeniero, como sabemos, tenía que remitir el levantamiento, y el arzobispado de Santiago, por su parte, una serie de documentos, de los que hablaré más adelante, relativos a estatutos y privilegios fundacionales. Como el tiempo pasaba y el croquis de Solinis no llegaba, el 2 de octubre determinaron "avisarle por el correo para que con la maior prontitud despache" ${ }^{\text {. }}$. En el ínterin, aprovechando que estaba trabajando "en los reparos y redificaciones de las casas, $y$ mas edificios, y al parezer conozersele capacidad en el arte" ${ }^{\prime 65}$, se pide al maestro carpintero Manuel Antonio Fandiño Vaamonde que "reconozca con cuidado todas las quiebras, y faltas que ay pormenor, y de ellas forme un plan discreptibo con expresion de su coste prudencial y echo y venido que sea el plan, y sentir del ex-

${ }^{61}$ Como apunté anteriormente, en planta se indica con la letra P.

${ }^{62}$ Francisco Solinis sitúa el altar en el muro occidental del salón.

63 A.H.N. Sección Consejos, leg. 16189, fols. 54 v.-55.

${ }^{64} i d e m$, fol. 55 . El día 8 de octubre anotaba el escribano que Francisco Solinis no "ha traido ni remetido el diseño, plan, o mapa de este monasterio y su situacion sin perxuicio de tenerle su Señoria escrito diferentes cartas al asumpto" (idem, fol. 58 v.).

65 idem, fol. $55 \mathrm{v}$. 
presado Solinis se junte uno y otro al auto antezedente" ${ }^{\text {"66 }}$. Por la fecha que figura en el plano, sabemos que el ingeniero concluyó su diseño el 10 de octubre; seis días más tarde ya estaba en poder del notario, pues justo en ese momento Fandiño presentó su presupuesto y ambos documentos se incluyeron en el expediente oficial. Aunque la relación de materiales y reparaciones calculada por el maestro carpintero es demasiado extensa para transcribirla íntegramente, se puede mencionar el importe de algunas partidas: la renovación de las cubiertas de las dos iglesias, entre vigas, pontones, tablas y guarniciones, costaría un total de 6512 reales; su entramado, otros $7141^{67}$; cambiar el piso de la sala destinada a las juntas de los canónigos, unos 2225 reales; y la rehabilitación de la "pared del cavildo asta los cimientos ${ }^{68}$, y materiales para ella", la nada despreciable cifra de 46603 reales $^{69}$.

Como el visitador real quería esclarecer y documentar el origen del cenobio y su naturaleza primitiva -interrogantes que todavía se siguen intentando aclarar en la actualidad-, solicitó al arzobispo Rajoy una serie de escrituras al respecto que se custodiaban en el archivo episcopal ${ }^{70}$. Pero además, "atendiendo a haber-

-

${ }^{66}$ ibidem.

${ }^{67}$ Las cubiertas de las iglesias, según indica Fandiño, estaban muy deterioradas: “...echo el computo del faiado, la armacion toda con la de la capilla de Santa Ysabel que esta arruinada lo mismo que la otra" (ídem, fol. 57).

${ }^{68}$ Interesan especialmente las medidas de esta dependencia, que, supongo, corresponde a la señalada en la planta de Solinis con la letra N: "Tiene trescientas y nobenta varas asta los cimientos de ocho quartas en quadro necisita cada braza de pared diez carros de piedra que ynportan tres mil setecientos y cinquenta reales... echo el computo de las trescientas y nobenta brazas de pared con su grueso correspondiente según arquitectura correspondiendole a braza, y media de alto, seis quartas y media de grueso desde alli al medio seis, desde el medio al piso cinco, y desde el piso al tejado quatro, para peones, erramientas para la manposteria, y vatideras de cal, maderas, y echura de estadas, clabos para ellas, desmolimiento de la obra ynportan doze mil quatrocientos reales" (idem, fols. $55 \mathrm{v}, 57$ ).

${ }^{69}$ ibidem.

${ }^{70}$ He aquí, en extracto, la carta que dirige Ares al arzobispo Rajoy el 18 de septiembre: “...Señor, voi procediendo en el ejercicio de visita de esto y vistos ya todos los documentos y memoriales de este archivo, nada se halla mas frequentemente en ellos, que razon de constituciones y Bullas Apostolicas: Pero ni vna Bulla, ni una de las tales constituciones paran aquí. Por testimonios, que hazen fé, consta, que en el año 1643 y siguientes se litigo pleito entre el Prior y canonigos o convento de aquí con el Fiscal eclesiastico de la Dignidad Arzobispal... que en dicho pleito se presentaron originales las Bullas y Privilegios Reales, como sele dado noticia de acordanza de grutas, cuebas, o hermitas en donde de antiguo se recojian $y$ hauitan los anacoretas, y hermitaños ${ }^{71}$, y de una capilla dedicada a santa Chrisptina y un hospital para los pobres y peregrinos de que apenas aunque ay la tradicion, no se hallan los bestigios"72, decide llevar a cabo una inspección en los alrededores de Caaveiro, "por si puede ynbestigarlos para mejor conocimiento del origen, y naturaleza de este santuario, monasterio yglesia" ${ }^{, 3}$. Ahora bien, antes de realizar la exploración prevista, y para evitar errores y pérdidas de tiempo innecesarias, Ares ordenó al escribano que iniciase las pertinentes diligencias informativas y convocase a algunos ancianos de la comarca para "examinarlos cerca de este punto, y hallando alguna certidumbre al caso pasar con ellos a los sitios" "74. El día 12 de septiembre, en cumplimiento del auto señalado, "concurrieron Diego de Villarino, Francisco Seco, Ramon Rodriguez y Pasqual Martinez vezinos de esta feligresia de Santiago de la Capela, y Domingo de Galdo de la de santa Maria de Cavalar de esta jurisdicion, quienes vaxo de juramento en forma examinados separadamente del caso dixeron ser ciertas las noticias de los santuarios que expresa el auto y con expecialidad quanto a la hermita de santa Chrisptina y casa de hospital para peregrinos romeros que venían en tiempo antiguo en romeria al glorioso san Juan, y que esta noticia, y tradicion era comun y bulgar en este pais, y la hauian oido a sus maiores, que decian haberlo oido a los suios, y que ademas de la hermita referida de santa Chrisptina hauia hauido otras hermitas, o grutas por el expacio de estos montes en que hauitauan los hermitaños de las que ya no se hallan vestigios, ni apenas de la referi-

asi mismo los estatutos, o constituciones, tambien originales, sobre el gobierno de este monasterio. Como S. M. quiere ser informado de todo, no puedo escusarme de no molestar a V. S. Ylustrisima suplicandole rendidamente se sirva mandar a su archivero... que de registrado el archivo me de aviso, y puntual razon de lo que hallare..." (A.H.D.S. Fondo General. Colegiatas. Caaveiro, carp. 366, s. f.).

${ }^{71}$ Esta noticia documental se ajusta a la propuesta, defendida por López Ferreiro y otros investigadores, de que bien pudo ser Caaveiro el resultado de un agrupamiento de eremitas o anacoretas que dio lugar a un cenobio benedictino, luego transformado en monasterio de canónigos regulares agustinos. Sobre este polémico asunto, véase C. CASTRO Álvarez, "S. Juan de Caaveiro: estado de la cuestión...", pp. 32-39.

\footnotetext{
72 A.H.N. Sección Consejos, leg. 16189, fol. 57 v.

73 ibidem.

74 ibidem.
} 
da de santa Chrisptina si que esta aun la acordaban y habian visto sus antepasados, y decian estar situada mas adelante del monasterio rio arriba cerca de la orilla del Eume al pie y falda de la sierra y monte que aun se conserba con el nombre de santa Chrisptina, y aunque fuimos a el no hallamos mas señal que un sitio cubierto de zarzas, y malezas, que dixeron los sobredichos ser el mismo de la capilla. Y quanto al hospital nos dixeron ser su sitio mas arriba en lo alto del monte en donde llaman Cincopernas adonde nos guiaron, y caminamos, y llegados no hallamos descubierto alguna pared mas que unos yndicios cubiertos ya de la maleza del monte, las que de mandato de su Señoria descubrieron y rexistraron con hazadones y reconocimos los cimientos de una pared y edificio quadrado de treinta y seis quartas de ancho, y quarenta y seis de largo; pero con el yndicio manifiesto de faltar su existencia mas ha de ducientos años por estar en la misma pared comprendido a la parte de arriba un castaño que yndica esta antiguedad y haberse ya criado en el sitio despues de estenguido el edificio, porque estando existente no podia hauerse plantado, nacido ni criado dentro ni en el grueso de la pared, todo lo qual asi hemos reconocido" ${ }^{, 75}$.

El arcediano de la catedral de Mondoñedo remite finalmente el expediente a Madrid e informa a la Real Cámara de su decisión de suspender temporalmente la elaboración de los estatutos por "el deplorable y lastimoso estado en lo material y en lo formal de la referida Colegial de Cabeiro", pues, según manifiesta Antonio Ares, la auténtica vida regular se había abandonado, "habiendo quedado solo como una sombra, y reduciendose todo el logro de los intereses y rentas, y en sustancia, a una pura ceremonia o formulario lastimoso" $" 76$. Por todas estas circunstancias desfavorables, propone al Fiscal de la Cámara "la traslacion de esta Colegial a la Parroquial de Puente de Eume, como se lo ha insinuado el Arzobispo de Santiago, o a la Castrense de Esteyro, como desea el Yntendente del Departamento del Ferrol"77.

La Real Cámara acogió favorablemente "el que haya suspendido Vuestra merced por

-

75 idem, fols. $58-58 \mathrm{v}$.

${ }^{76}$ A.H.D.S. Fondo General. Colegiatas. Caaveiro, carp. 366, s. f.

77 idem. ahora la formacion de estatutos que se le encargo por los justos motibos que ha expuesto", y también aprobó el traslado de la colegiata, pero, eso sí, el proyecto final tenía que ser estudiado en detalle y todos los implicados ponerse de acuerdo ${ }^{78}$. Con todo, el plan fue abandonado. Tiempo después, en el año 1788, se intentó un nuevo traslado - esta vez al convento de los franciscanos de Ferrol-, que tampoco se llevó a cabo finalmente ${ }^{79}$.

\section{APÉNDICE DOCUMENTAL}

Plano general de la Real Colegiata de San Juan de Caaveiro con la demostración de los montes y ríos que la circundan. Francisco Solinis. Ferrol, 10 de octubre de 1769. Tinta negra y aguadas de colores sobre papel. Tiene escala gráfica de 200 pies castellanos. Firma y rúbrica de Francisco Solinis (A.H.N. Sección Consejos. Mapas, planos y dibujos, $\mathrm{n}^{\circ}$ 640).

Anotaciones manuscritas: Explicacion. A. Camino que va de Ferrol al Santuario/ B. Puente/ C. Sitio que sirve de entrada, donde á mucha costa se puede edificar/D. Unica entrada para el Collegio/ E. [Comu]nicacion para entrar a las havi[tac]iones, y paso preciso para la Yglesia/ [F. Havi]taciones para los seis Prebenda[dos]/ G. Casa arruynada/ H. Casa por concluir/ I. Atrio descubierto delante de la Yglesia/ J. Yglesia/ K. Sacristia/ L. Corredor que sirve de paso/ M. Yglesia que no tiene uso/ N. Sala de Capitulo/ O. Archivo/ P. Salon arruynado que sirve de Yglesia en los concursos de Romerias/ Q. Pared con pie y medio de desplome azia adentro que causa la ruyna de dicho Salon/ R. Coro [...] subida para la Torre/ S. Cavall[erizas]/ T. [Horno]/X. Fuente/ Y. Varios Sitios de Viñas, y tierras de labor/ Z. Camino, que baxa á passar el Puente del Rio Heumel \&. Monte de Vininzon/ W. Ydem de Penamalal. Ydem de Pardineyra/ Nota: El piso del Collegio se halla cincuenta pies mas alto, que el del Horno T. Encima del Archivo O. y Sala de juntas, $N$, hay un segundo piso que sirve de estrecha Havitacion, cuando concurre el Prior, y tiene la entrada por el Coro R./ Escala de 200 Pies Castellanos/ Ferrol 10 de Octubre de 1769/Francisco Solinis.

\footnotetext{
78 idem.

79 J.F. CORREA ARIAS, “Caaveiro e a crise...”, p. 195.
} 


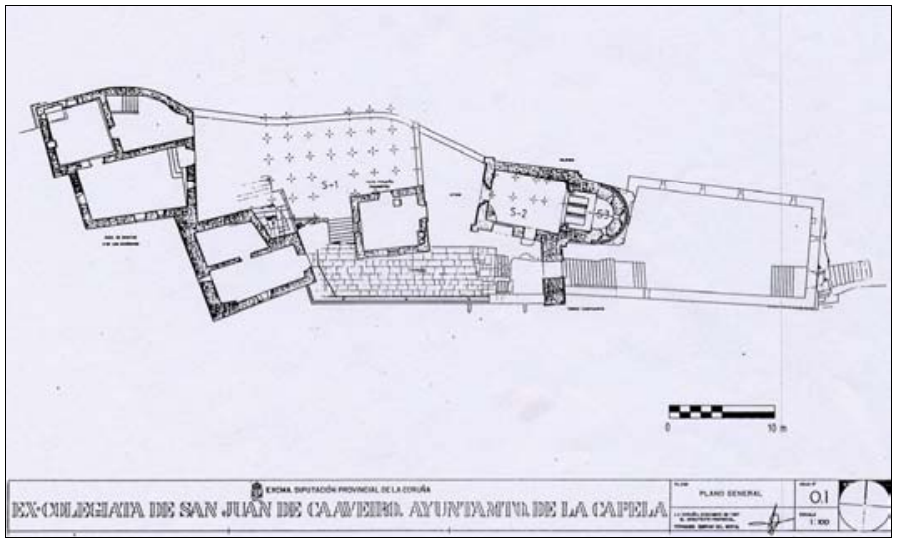

- Fig. 1. Plano General de la Colegiata de San Juan de Caaveiro (Diputación Provincial de A Coruña).

PLANTA GENERAL DE SAN JUAN DE CAAVEIRO

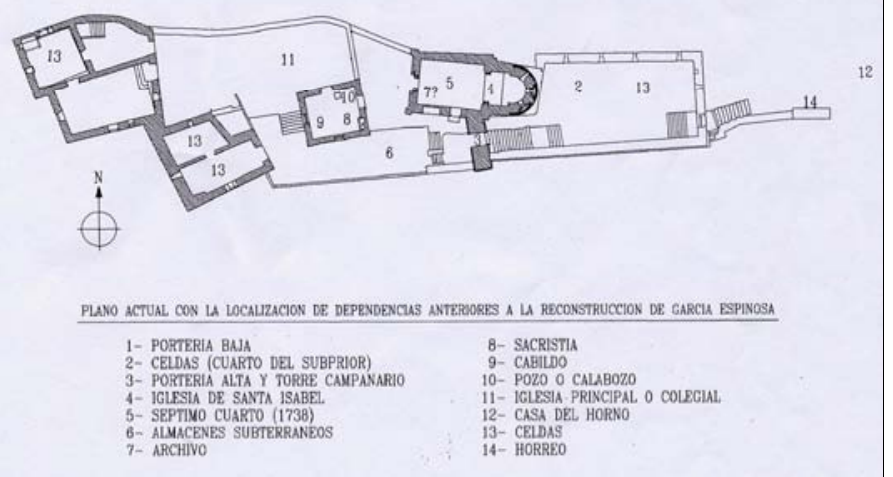

- Fig. 2. Planta del monasterio. Fernando Sarmiento.

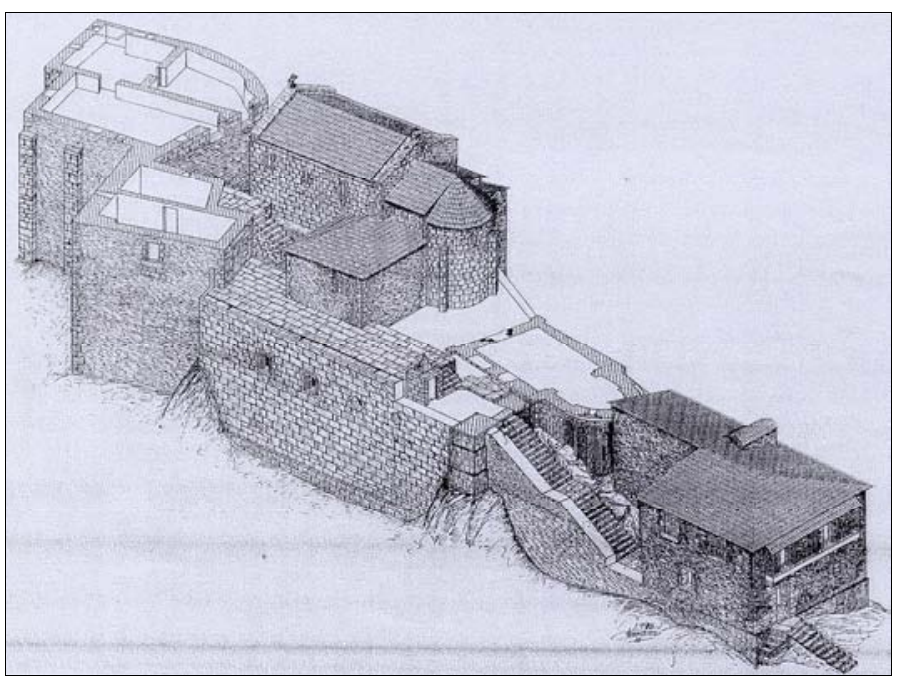

- Fig. 3. Reconstrucción hipotética de los edificios desaparecidos. Fernando Sarmiento. 


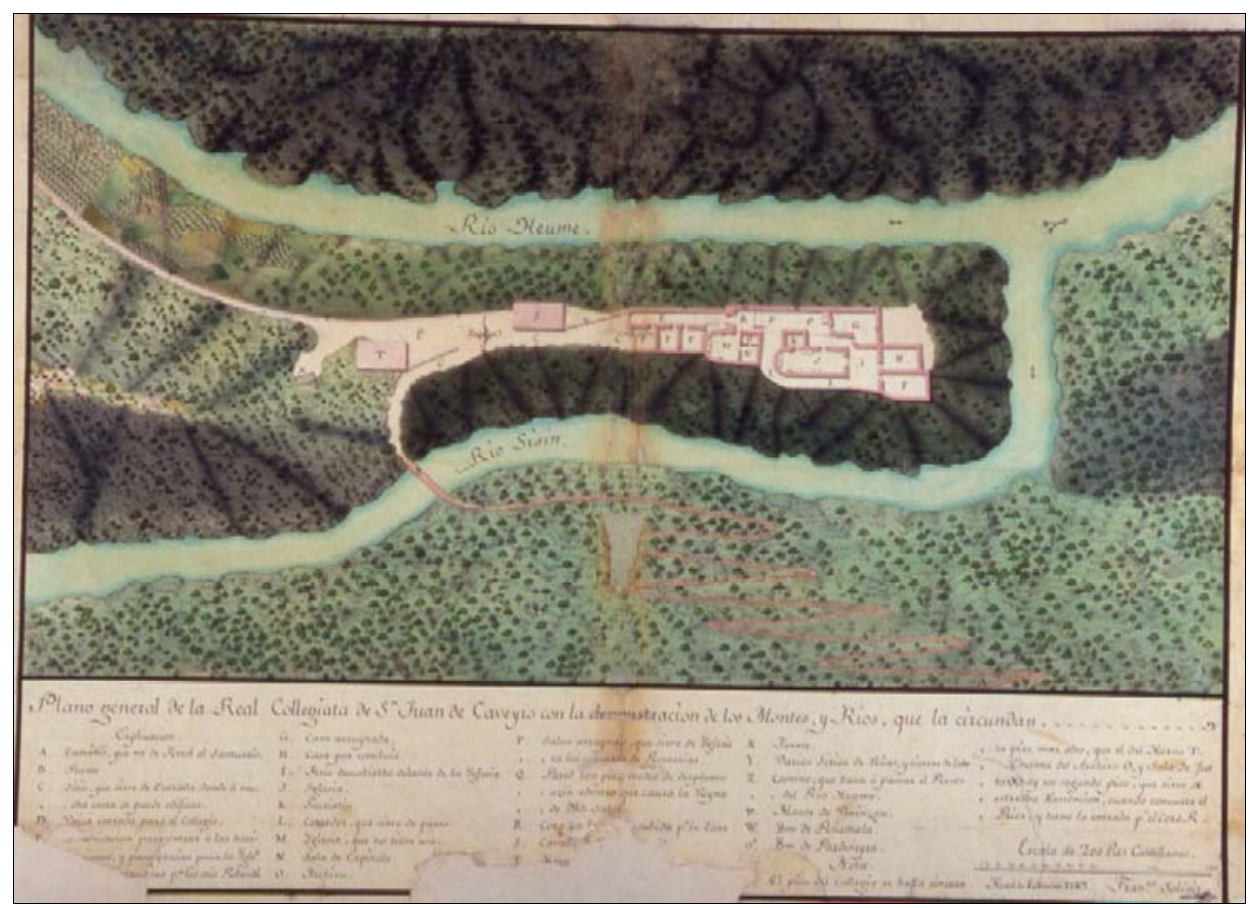

- Fig. 4. Plano General de la Colegiata de San Juan de Caaveiro con los montes y ríos que la circundan. 1769. Francisco Solinis (A.H.N.).

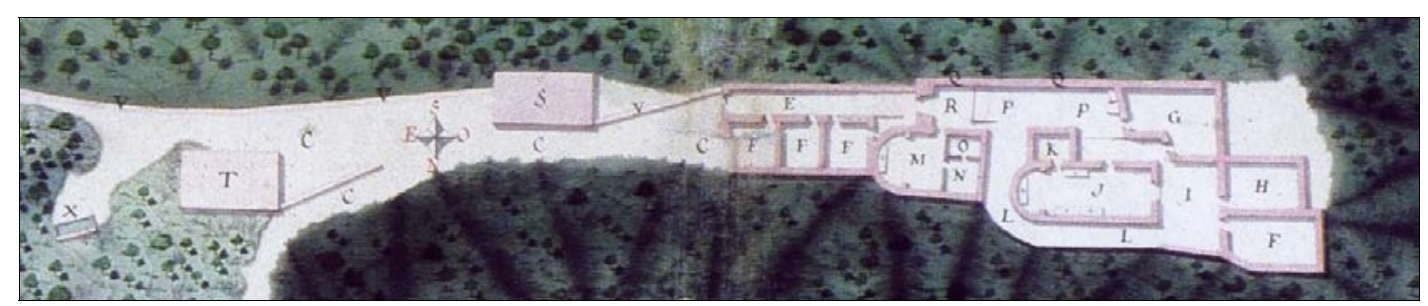

- Fig. 5. Real Colegiata. Detalle de la planta. 1769. Francisco Solinis (A.H.N.). 